\title{
ASYMPTOTIC STABILITY OF A PERTURBED ABSTRACT DIFFERENTIAL EQUATIONS IN BANACH SPACES
}

\author{
HANEN DAMAK AND MOHAMED Ali Hammami
}

Abstract. This paper is mainly concerned with the asymptotic stability of the solutions of a perturbed abstract differential equation in Banach spaces. Let $A$ be a generator of an exponentially stable operator semigroup and let $C(t), t \geqslant 0$ be a linear bounded variable operator. Assuming that the perturbation $F(t, x)$ is sufficiently small norm for the equation $\frac{d x}{d t}=$ $A x+C(t) x+F(t, x)$, we derive the Lyapunov asymptotic stability conditions. These results are applied to partial differential equations.

Mathematics subject classification (2010): 12H20, 47D03, 93D20, 35R15.

Keywords and phrases: Abstract differential equations, semigroups of linear operators, asymptotic stability, partial differential equations on infinite-dimensional.

\section{REFERENCES}

[1] N. CHAFEE, A stability analysis for a semilinear parabolic partial differential equation, Journal of Differential Equations 15 (1974), 522-540.

[2] R.F. CURTAin, Stability of stochastic partial differential equation, Journal of Mathematical Analysis and Applications 79 (1981), 352-369.

[3] H. Damak And M.A. Hammami, Stabilization and Practical Asymptotic Stability of Abstract Differential Equations, Numerical Functional Analysis and Optimization 37 (2016), 1235-1247.

[4] M. GIL, Integrally small perturbation of semigroups and stability of partial differential equations, International Journal of Partial Differential Equations 2013 (2013).

[5] M.I. GIL, Stability of Finite and Infinite Dimensional Systems, Kluwer Academic Publishers, Boston, Mass, USA (1998).

[6] G. GUHRING AND F. RABIGER, Linearized stability for semilinear non-autonomous evolution equations with applications to retarded differential equations, Ulmer Seminare 2 (1997).

[7] A.V. ION, Lyapunov stability of the zero solution of a perturbed abstract parabolic non-autonomous equation, ROMAI Journal 4 (2008), 105-114.

[8] V. LAKShmikantham, V.M. Mastrov And S. Sivasundaram, Vector Lyapunov Functions and Stability Analysis of Nonlinear Systems, Kluwer Academic, Dordrecht, The Netherlands (1991).

[9] Z. Luo, B. Guo And O. Morgul, Stability and Stabilization of Infinite Dimensional Systems With Applications, Springer, London (1999).

[10] S. MARX, Y. CHITOUR AND C. PRIEUR, Stability analysis of dissipative systems subject to nonlinear damping via Lyapunov techniques, arXiv:1808.05370v1, (2018).

[11] C.V. PAO, Nonlinear Parabolic and Elliptic Equations, Plenum Press, New York, NY, USA (1992).

[12] A. PAZY, Semigroups of Linear Operators and Applications to Partial Differential Equations, Springer, New York, NY, USA (1983).

[13] V.A. TRENOGIN, Lyapunov theorem about the stability by linear approximation as the consequence of the implicit operators theorem, Doklady Academii Nauk 407 (2006), 742-746.

[14] V.A. Trenogin, Asymptotic stability of trivial solution of differential equations with unbounded linearity, in Banach spaces, ROMAI Journal 3 (2007), 207-212.

[15] V.A. TRENOGIN AND ANCA-V.ION, New results in the stability study of non-autonomous evolution equations in Banach spaces, Journal of Mathematics and Applications (2010), No 33, 117-127.

[16] A.L. ZuEv, Partial asymptotic stability of abstract differential equations, Ukrainian Mathematical Journal 58 (2006), 709-717. 